\title{
A SURVEY OF LIVESTOCK AND POULTRY ALONG WITH MORTALITY TRENDS OF GOAT AT KAUNIA UPZILLA, RANGPUR, BANGLADESH
}

\author{
F. Rabbi ${ }^{1 *}$ M. S. Mannan ${ }^{3}$, M. A. Imtiaz ${ }^{1}$, S. Chowdhury ${ }^{4}$ and M. A. M. Prodhan ${ }^{2}$ \\ ${ }^{1}$ Department of Physiology, Biochemistry and Pharmacology, ${ }^{2}$ Department of Medicine and Surgery \\ ${ }^{3}$ Department of Microbiology, ${ }^{4}$ Department of Pathology and Parasitology, Chittagong Veterinary and Animal \\ Sciences University (CVASU), Khulshi, Chittagong, Bangladesh-4225
}

\begin{abstract}
This investigational survey was carried out to explore the livestock along with mortality of goat at eight different villages of Kaunia upzilla, Rangpur, Bangladesh from $10^{\text {th }}$ March to $10^{\text {th }}$ July 2013. A pre-structured questionnaire data were collected based on livestock, breed, age, sex, housing pattern, grazing, vaccination and deworming history, diseases, treatment, causes of death with mortality. A total of 808 species of livestock and poultry were recorded through survey where $38 \%$ were goat and $42.5 \%$ were poultry. Only $6.5 \%$ livestock were vaccinated and $7 \%$ were dewormed. Statistically significant difference in vaccination and deworming was reputed with different breeds $(p \leq 0.05)$ whether no significant variation was observed with sex and grazing $(p>0.05)$. About $42.24 \%$ goat kids were mortal due to coldness, pneumonia along with diarrhea $(37.5 \%)$, coccidiosis (37.21\%) and Peste des Petits Ruminants (PPR) (14.86\%). PPR was the major focal cause of mortality in adult male $(33.11 \%)$, female $(28.38 \%)$ and growing goat $(23.65 \%)$ which was followed by diarrhea, coccidiosis, pneumonia, urogenital infection, dystocia and poisoning. The study has assessed probable mortality, diseases and hazards of goat rearing which should be subsided and clinically managing as well. However, extensive work with preventive intervention (regular deworming, vaccination) and improvement of husbandry practices are suggested for the expansion of goat rearing in Bangladesh.
\end{abstract}

Key words: Survey, vaccination, deworming, mortality

\section{INTRODUCTION}

Livestock is an integral sector of agricultural economy of Bangladesh performing multidimensional functions such as provision of food, nutrition, income, savings, draft power, manure, transport, social and cultural functions (Tareque and Chowdhury, 2010). Small ruminants especially goat is very important in rural economy and nutrition and has the potentially using it as a tool for poverty reduction in Bangladesh (Ershaduzzaman et al., 2007). It is considered as the poor man's cow (Kashem et al., 2011), reared in backyard system by rural farmers, especially the poor women or children as an integral part of the farming system (Chowdhury et al., 2003). The higher demands for meat and especially for skin in the local as well as foreign markets focused the goat enterprise extremely prominent to the vulnerable groups of people and the existing socioeconomic condition of the country (Hassan et al., 2011). Management system is a combination of both tethering and scavenging with or little inputs for breeding, feeding \& health care (Saadullah and Hossain, 2000).

Different types of diseases both infectious and non-infectious are significant problems in goat rearing in our country. A great damage caused by infectious diseases and also creates nutritional deficiency and disturbances in fertility. It has been reported that about $10 \%$ animals die annually because of diseases (Ali et al., 2011). Among them Peste des Petits Ruminants (PPR), goat pox, pneumonia, enterotoxaemia, tetanus, brucellosis, mastitis and metritis, mycotic diseases, conjunctivitis, diarrhea and parasitic gastro-enteritis are the most important causes of mortality in small ruminants in tropical country like Bangladesh (Kashem et al., 2011). As Kaunia upzilla, Rangpur is one of the goat pocket area in Bangladesh with available feed resources where people have an enormous opportunity to change their livelihood and increase their proceeds by goat rearing. But they faced diverse problems due to attack on a variety of diseases as well as huge mortality which had a limited data in whole country especially on my study that area. So the aim of this study is to explore livestock and poultry along with mortality trends of goat rearing at Kaunia, Rangpur, Bangladesh.

*Corresponding e-mail address: frsumona@gmail.com

Copyright (c) 2014 Bangladesh Society for Veterinary Medicine

All rights reserved 0304/2014 


\section{F. Rabbi and others}

\section{MATERIALS AND METHODS \\ Area and duration of work}

Rangpur is the fast growing small scale goat rearing pocket in Bangladesh. It has a tropical wet and dry climate which is generally marked with monsoons, high temperature, considerable humidity and heavy rainfall. Purposively this study was conducted on eight villages at Kaunia upzilla of Rangpur district namely as Arajikanua, Jigabari, Nijdorpa, Rajib-2, Rajib-4, Sadrataluk-1, Sadrataluk-2 and Sadrataluk-3 where all the villagers rearing livestock and poultry were included in this study. It was carried out for a period of four months from $10^{\text {th }}$ March to $10^{\text {th }}$ July 2013.

\section{Questionnaire design and data collection}

On the farm visit, a pre-structured questionnaire survey was used to collect relevant information of livestock. A closed ended (categorical) questionnaire was designed according to Thrushfield (2005). Data were collected by face to face interaction with the responded farmer, repeated questioning, observation of animal and recorded based on livestock, breed, age [in case of goat, kid ( $\leq 3$ months), growing goat (3-24months) and adult (> 24months)], sex, housing pattern, floor (Katcha/ dirty/ muddy/ brick/ concrete/ rubber bedded), grazing (or zerograzing), vaccination and deworming history, rearing system (intensive or semi-intensive), diseases, treatment, causes of death with mortality. Data were also sought out from the clinical cases of different diseases on goat of the farmers.

\section{Disease identification and examination}

Disease was identified with owner's complaint, history of weakness, onset and duration of illness, identification of feasible risk factors (flock history/crowding) and clinical examination of animal. General attitude (alertness/ dullness/ depression), posture (normal/ lameness), gait (normal/ defective) and body condition of animal (Cachectic/ poor/ fair/ good/ fat/ over fat) were carefully inspected by distant inspection (Radostits $e t$ al., 2000). Diagnoses were also based on clinical signs, gross observation (dirrheatic/non-dirrheatic), fecal consistency, micturation, abscess, hair coat, ecto-parasites, maggots, skin abnormalities, skin lesions with crust, scale, dandruff or foul odorous discharge) and response to treatment in case of poisoning.

Mainly PPR was diagnosed on the basis of clinical findings as sudden rise on temperature (104-106 $\left.{ }^{\circ} \mathrm{F}\right)$, profuse diarrhea accompanied by dehydration with severe salivation and muco-purulent nasal discharge. Pneumonia was identified through severe coughing with dyspnoea, presence of serous and muco-purolent (later stage) nasal discharge, rough hair with increase temperature $\left(104-105^{\circ} \mathrm{F}\right)($ Fraser et al., 1991).

\section{Data analysis}

Data that were collected had been stored into MS Excel (Microsoft office Excel-2007, USA). Descriptive analysis was performed by STATA version 12.1 (STATA Corporation, Texas, USA) to estimate the association between a categorical explanatory variable with outcome and then chi-square $\left(\chi^{2}\right)$ test was done. An association was considered as significant if $\mathrm{p} \leq 0.05$.

\section{RESULTS AND DISCUSSION}

\section{Survey of livestock and poultry at Kaunia}

The survey revealed 808 total livestock and poultry during the survey period where cattle were $13.5 \%$, goat $37.5 \%$, Sheep $6.5 \%$ and poultry $42.5 \%$. Most livestock were not vaccinated and dewormed, only $6.5 \%$ were vaccinated and $7 \%$ were dewormed (Table 1 ).

Small ruminants especially goat is very significant in rural economy and nutrition. This study showed that among ruminants goat is the first preference to rear. About $37.5 \%$ goats were reared at Kaunia upzilla which is agreed with Ershaduzzaman et al., 2007. Smallholder livestock production predominates; with over $70 \%$ of rural families keep Black Bengal along with some Jamunapari and their crosses with Black Bengal of local primarily as sources of investment, manure and meat at home or during festivals. Goats are allowed to rear throughout the seasons, thriving on indigenous browses growing in compound bushes and farm fallows with additional supplementation from kitchen wastes which is agreed with Okoli et al. (2003). Prophylactic management of common infectious diseases is rarely practiced; few animals are dewormed or vaccinated. 
Table 1. Livestock survey on eight villages at Kaunia upzilla of Rangpur

\begin{tabular}{|c|c|c|c|c|c|c|c|c|c|}
\hline \multirow[t]{2}{*}{ Villages } & \multirow[t]{2}{*}{ Cattle } & \multirow[t]{2}{*}{ Goat } & \multirow[t]{2}{*}{ Sheep } & \multirow[t]{2}{*}{ Poultry } & \multirow{2}{*}{$\begin{array}{l}\text { Grand } \\
\text { Total }\end{array}$} & \multicolumn{2}{|c|}{ Vaccination } & \multicolumn{2}{|c|}{ Deworming } \\
\hline & & & & & & Yes & No & Yes & No \\
\hline Rajib-2 & 17 & 46 & 7 & 42 & 112 & 10 & 15 & 10 & 20 \\
\hline Rajib-4 & 10 & 36 & 4 & 33 & 83 & 5 & 11 & 4 & 12 \\
\hline Nijdorpa & 20 & 42 & 5 & 45 & 112 & 6 & 15 & 7 & 17 \\
\hline Jigabari & 16 & 31 & 3 & 40 & 90 & 10 & 9 & 12 & 7 \\
\hline Arajikanua & 15 & 48 & 9 & 65 & 137 & 9 & 21 & 9 & 22 \\
\hline Sadrataluk-1 & 9 & 35 & 6 & 53 & 103 & 5 & 12 & 4 & 13 \\
\hline Sadrataluk-2 & 10 & 37 & 9 & 39 & 95 & 3 & 17 & 5 & 15 \\
\hline Sadrataluk-3 & 11 & 27 & 8 & 30 & 76 & 4 & 13 & 5 & 12 \\
\hline Total N (\%) & $\begin{array}{l}108 \\
(13.5)\end{array}$ & $\begin{array}{l}302 \\
(37.5)\end{array}$ & $51(6.5)$ & $\begin{array}{l}347 \\
(42.5)\end{array}$ & 808 & $52(6.5)$ & $113(14)$ & $56(7)$ & $\begin{array}{l}118 \\
(14.6)\end{array}$ \\
\hline
\end{tabular}

Association of variables with vaccination, deworming and grazing of goat at Kaunia

The association of breed and sex with vaccination, deworming and grazing is depicted in Table 2 (BB = Black Bengal, $\mathrm{JM}=$ Jamnapari and Cross $=\mathrm{BB} \times \mathrm{JM})$. It is analyzed that statistically significant variation with vaccination and deworming are observed in different breeds of goat $(\mathrm{p} \leq 0.05)$ whether they are insignificant in sex $(p>0.05)$. It is due to genetic variation of different breeds and adaptation with climatic change on global weather. Moreover, lack of awareness of goat owners for vaccination and deworming; inadequate veterinary services with vaccines, drugs and medicaments along with their high purchasing system (Imtiaz and Rana, 2014; Rabbani et al., 2004); lack of storage and transportation facilities of vaccines or other sophisticated drugs; irregular communication between veterinarians and owners; huge working burden of field veterinarians with scarce manpower (Rahman and Rana, 2013; Bangladesh National Livestock Development Policy, 2007) are the apparent health hazards to provide significant variation with vaccination and deworming. It is also estimated that no significant variation is recognized on breed and sex with the grazing pattern $(\mathrm{p}>0.05)$. In Bangladesh, free range or scavenging system of rearing goat is followed from the history of beginning of the country which is also carried out in this study. Sometimes semi-scavenging or semi-intensive rearing system is observed but intensive rearing for goat is very rare. So there is no observed variation in type of grazing with breed and sex of goat.

\section{Mortality of goat \\ Kid mortality}

After birth, immunologically kids are weak or sick; they are suffering a lot of infectious diseases or disease condition. In this study, it was found from Table 3, pneumonia was the prime cause of kid mortality (42.24\%) which is exactly similar with Chowdhury et al. (2002) (Pneumonia 42.39\%). On the last decade in the year 19801990s, Sriram et al. (1982) and Koul et al. (1988) also observed that main causes of kid mortality were pneumonia and enteritis which is continued in this $21^{\text {st }}$ decade. But Kashem et al. (2011), Ershaduzzaman et al. (2007) observed somewhat less severe case of pneumonia where Kashem said $21.15 \%$ and Ershaduzzaman $27 \%$. Other hand, major causes of kid mortality were infectious where kids were died due to diarrhea (37.5\%), 


\section{F. Rabbi and others}

coccidiosis(37.21\%) and PPR (14.86\%) which is coincide with Kashem et al. (2011) (PPR 25\%, Diarrhea 17.31\%); Ershaduzzaman et al. (2007) (Diarrhea 30\%) and Chowdhury et al. (2002) (Diarrhoea 32.61\%).

Table 2. Association of variables with vaccination, deworming and grazing of goat

\begin{tabular}{lllll}
\hline \multicolumn{2}{l}{ Category: Vaccination } & & & \\
Variables & Level & Vaccinated N (\%) & Non-vaccinated N (\%) & p value \\
\hline Breed & BB & $44(27)$ & $122(73)$ & 0.01 (Significant) \\
& Cross & $17(22)$ & $61(78)$ & \\
& JM & $25(43)$ & $33(57)$ & 0.59 (Insignificant) \\
& Fex & $57(28)$ & $150(72)$ & \\
& Male & $29(31)$ & $66(69)$ &
\end{tabular}

\section{Category: Deworming}

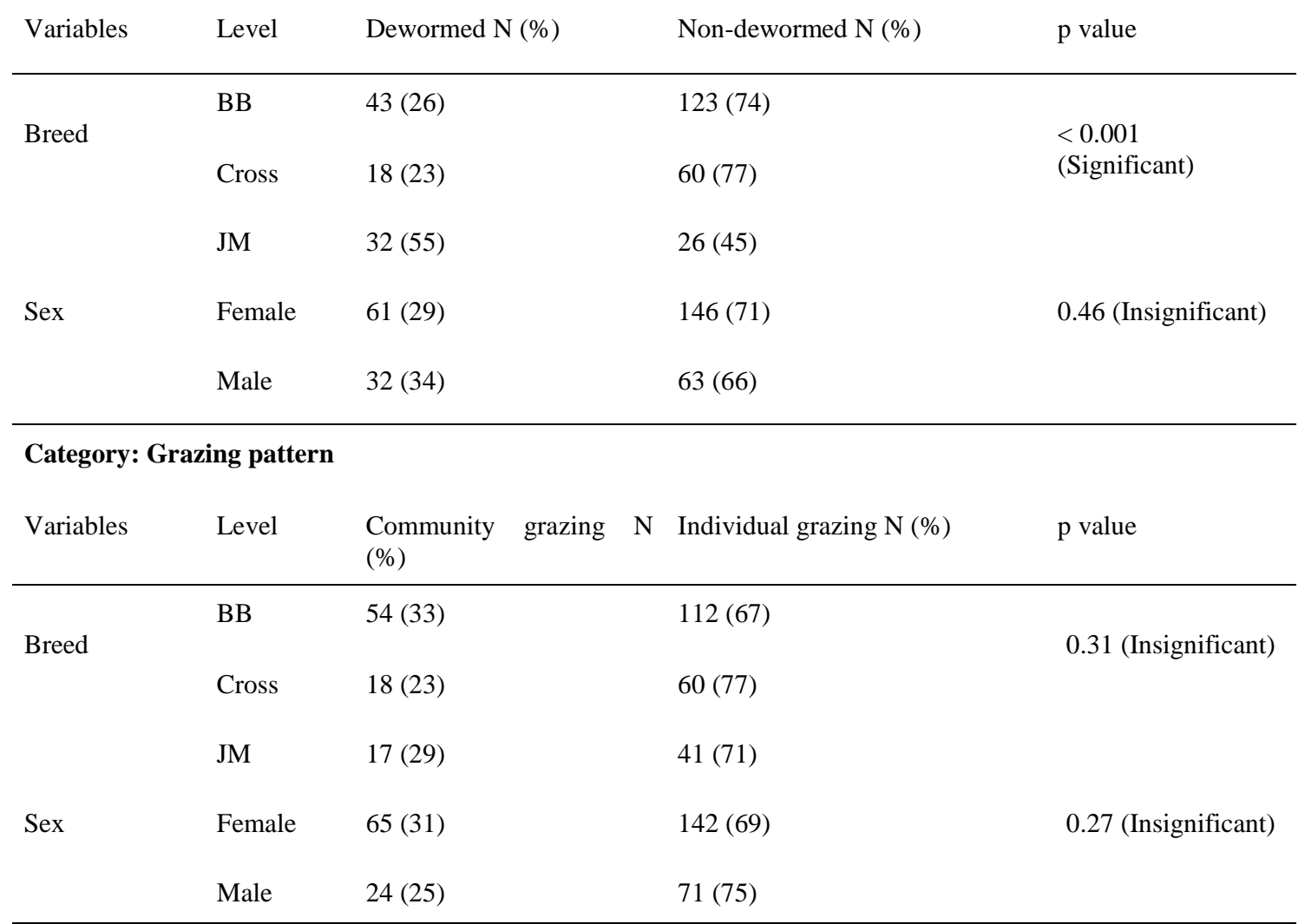




\section{Growing and adult goat mortality}

On the growing stage and at the adult age, immunity develops and also acquires. But at that period goat are robustly affected with different infectious causes. In the survey, growing goat were died due to coccidiosis $(34.88 \%)$, PPR (23.65\%) and diarrhea (22.73\%) (Table 3).

Table 3. Mortality of goat at Kaunia

\begin{tabular}{llllll}
\hline Cause of death & Kid $(\%)$ & $\begin{array}{l}\text { Growing goat } \\
(\%)\end{array}$ & $\begin{array}{l}\text { Adult goat } \\
(\text { female })(\%)\end{array}$ & $\begin{array}{l}\text { Adult goat (male) } \\
(\%)\end{array}$ & Total (N) \\
\hline Pneumonia & $49(42.24)$ & $30(25.86)$ & $15(12.93)$ & $22(18.97)$ & 116 \\
PPR & $22(14.86)$ & $35(23.65)$ & $42(28.38)$ & $49(33.11)$ & 148 \\
Coccidiosis & $16(37.21)$ & $15(34.88)$ & $5(11.63)$ & $7(16.28)$ & 43 \\
Diarrhea & $33(37.5)$ & $20(22.73)$ & $20(22.73)$ & $15(17.05)$ & 88 \\
Poisoning & 0 & 0 & $5(62.5)$ & $3(37.5)$ & 8 \\
Dystocia & 0 & 0 & $7(100)$ & 0 & 7 \\
Urogenital & 0 & 0 & 0 & $9(100)$ & 9 \\
Accident & 0 & 0 & $5(83.33)$ & $1(16.67)$ & 6 \\
\hline
\end{tabular}

Pneumonia is reduced from their kidding age (25.86\%). Ershaduzzaman et al. (2007) revealed highest number of growing goat was died due to diarrhea (34\%) and pneumonia $(28 \%)$ where a small number due to enterotoxaemia (10\%) and bloat (7\%).

PPR was the major focal cause of mortality in male $(33.11 \%)$ than female $(28.38 \%)$ which is agreed with Sarker and Islam (2011); Rahman et al. (2004). This disease is frequently occurred at the rainy season compared to drier and colder season observed by Islam et al. (2001) which is coincided with the survey period of this study. Kashem et al. (2011) reported as highest percentage of adult mortality was due to PPR (38\%) followed by pneumonia (24.14\%) within the infections and other infectious causes such as diarrhea (13.8\%) and contagious ecthyma (13.8\%) found in adult goat. However, in the study area diarrhea was very common in both female $(22.73 \%)$ and male (17.05\%) whether it was continued with pneumonia (female $12.93 \%$ and male $18.97 \%$ ); coccidiosis (female $11.63 \%$ and male 16.28\%) those are similar with Noman et al. (2011). Furthermore, Noninfectious causes likely poisoning (female 62.5\% and male 37.5\%); accident (female $83.33 \%$ and male $16.67 \%$ ) had lower effects on adult goat mortality which is also approved with Kashem et al. (2011). Pregnant female were mostly died during difficulties in parturition. They were failed to deliver kid due to dystocia and died. On urogenital infection male were generally infected and died due to urolithiasis.

\section{CONCLUSION}

Different types of diseases infectious and non-infectious both are important hazards and problems in goat rearing of our country. It can be concluded that among the infectious diseases PPR, pneumonia, diarrhea, coccidiosis and other many more diseases cause high mortality in all ages of goat at Kaunia upzilla, Rangpur. The mortality of goat is associated with irregular vaccination and deworming along with improper husbandry practices. From the present study, it is suggested that extensive work is needed for deduction of adult mortality by appropriate management practices and preventive (vaccine or deworming) intervention.

\section{ACKNOWLEDGEMENTS}

The author would like to give thanks to goat reared and the correspondents for their cordial cooperation during the survey period. 


\section{F. Rabbi and others}

\section{REFERENCES}

1. Ali MH, Bhuiyan MKJ and Alam MM (2011). Retrospective epidemiologic study of diseases in ruminants in Khagrachari hill tract district of Bangladesh. Bangladesh Journal of Veterinary Medicine 9 (2): 145-153.

2. Bangladesh National Livestock Development Policy (2007). Ministry of Fisheries and Livestock, Govt. of the People's Republic of Bangladesh, Dhaka. http://www.mofl.gov.bd/pdf/Livestock_Policy-Final\%20copy.pdf (Accessed date $3^{\text {rd }}$ May, 2014).

3. Chowdhury SA, Shill BK and Hossain SMJ (2003). Chagolpalon manual. $2^{\text {nd }}$ edn, Bangladesh Livestock Research Institute (BLRI), Savar, Dhaka-1341.

4. Chowdhury SA, Bhuiyan MSA and Faruk S (2002). Rearing Black Bengal Goat under Semi-Intensive management, Physiological and Reproductive Performances. Asian-Australasian Journal of Animal Sciences 15 (4): 477-484.

5. Ershaduzzaman M, Rahman M, Roy BK and Chowdhury SA (2007). Studies on the diseases and mortality pattern of goats under farm conditions and some factors affecting rates in Black Bengal kids. Bangladesh Journal of Veterinary Medicine 5 (1 and 2): 71-76.

6. Fraser MC, Bergeron JA, Mays A and Aiello SE (1991). Digestive system (coccidiosis, intestinal diseases in ruminants), Generalized condition (Peste Des Petits Ruminant), Masculoskeletal system (foot rot), Reproductive system (mastitis), Respiratiry system (introduction, pneumonia). In: The Merck Veterinary Manual. Seventh edition, Merck \& Co. Inc. Rahway, NJ, USA, p. 103-755.

7. Hassan MM, Hoque MA, Islam SKMA, Khan SA, Roy K and Banu Q (2011). A prevalence of parasites in Black Bengal Goats in Chittagong, Bangladesh. International Journal of Livestock Production 2 (4): 40-44.

8. Imtiaz MA and Rana S (2014). Problems faced by the small scale dairy owners in receiving veterinary services in selected areas of Chittagong. Bangladesh Journal of Veterinary Medicine 12 (1): 63-65.

9. Islam MR, Shahidullah M, Rahman MA, Das PM and Dewan ML (2001). Prevalence of PPR of goat and their response to antibiotic treatment at Mirzaganj Upazila of Patuakhali district. Journal of Environmental Sciences and Natural Resources 5 (2): 181-184.

10. Kashem MA, Hossain MA, Ahmed SSU and Halim MA (2011). Prevalence of diseases, morbidity and mortality of Black Bengal Goats under different management systems in Bangladesh. University Journal of Zoology, Rajshahi University 30: 01-04.

11. Koul GL, Somvansha S and Biswas JC (1988). Mortality pattern in Pashmina goats. Indian Veterinary Journal 65: 847-849.

12. Noman MA, Shaikat A, Nath B, Shil S and Hossain M (2011). Incidence and modulating effects of environmental factors on infectious diseases of Black Bengal Goat in Cox's Bazar district of Bangladesh. YYU Veterier Fakultesi Dergisi 22 (3): 163-167.

13. Okoli IC, Ebere CS, Uchegbu MC, Udah CA and Ibeawuchi II (2003). Survey of the diversity of plants utilized for small ruminant feeding in Southeastern Nigeria. Agricultural Ecosystem and Environment 96: 147-154.

14. Rabbani MS, Alam MM, Ali MY, Rahman SMR and Saha BK (2004). Participation of rural people in dairy enterprise in a selected area of Bangladesh. Pakistan Journal of Nutrition 3 (1): 29-34.

15. Radostits OM, Gay CC, Blood DC and Hinchcliff KW (2000). Clinical examination and making a diagnosis In: Veterinary Medicine, A textbook of the diseases of cattle, sheep, pigs, goats and horses. $9^{\text {th }}$ edn, WB Saunders Co., Philadelphia p. 03-40.

16. Rahman AU, Ashfaque M, Rahman SU, Akhtar M and Ullah S (2004). Pest des Petits Ruminants antigen in mesenteric lymphnodes of goats slaughtered at D.I. Khan. Pakistan Veterinary Journal 2: 159-160.

17. Rahman MH and Rana S (2013). Farmer's constraints in receiving animal health services in rural areas of Bangladesh. Bangladesh Journal of Veterinary and Animal Sciences 2: 21-27.

18. Saadullah M and Hossain MM (2000). Quantification of locally available feed resources and feeding systems of animals in different regions of Bangladesh. Project Report, Bangladesh Agricultural Council.

19. Sarker S and Islam MH (2011). Prevalence and risk factor assessment of Peste des Petits Ruminants in goats in Rajshahi, Bangladesh. Veterinary world 4 (12): 546-549.

20. Sriram PK, Rao PR and Naidu NGR (1982). Goat mortality in Andhra Pradesh. Indian Veterinary Journal 59: 9699.

21. Tareque AMM and Chowdhury SMZH (2010). Agricultural Research Priority: Vision 2030 and beyond. Bangladesh Agricultural Research Council. Farmgate, Dhaka.

22. Thrusfield MV (2005). Criteria for Success of Questionnaire. In: Veterinary Epidemiology. $3^{\text {rd }}$ edn, Oxford, UK: Blackwell Science p. 189-213. 